\title{
Elastose Perfurante Serpiginosa e Doença de Wilson: Uma Consequência Rara, mas Previsível da Terapêutica a Longo Prazo com D-Penicilamina
}

\section{Elastosis Perforans Serpiginosa and Wilson Disease: A Rare but Predictable Consequence of Long-term Therapy with D-Penicillamine}

\author{
André PINHO $\otimes^{1}$, José Carlos CARDOSO ${ }^{1}$, Miguel GOUVEIA ${ }^{1}$, Hugo OLIVEIRA ${ }^{1}$ \\ Acta Med Port 2016 Mar;29(3):227-230 - http://dx.doi.org/10.20344/amp.6749
}

\section{RESUMO}

A elastose perfurante serpiginosa é uma dermatose perfurante rara, encontrada sobretudo em adolescentes e adultos jovens, caraterizada pela eliminação transepidérmica de fibras elásticas anómalas. O único fármaco conhecido capaz de induzir elastose perfurante serpiginosa é a D-penicilamina. Descrevemos o caso de uma doente de 52 anos com pápulas queratósicas confluentes com disposição anular e crescimento centrífugo, localizadas na região cervical anterior. A doente estava cronicamente medicada com D-penicilamina, por doença de Wilson. A biópsia lesional revelou eliminação transepidérmica de fibras elásticas com aumento da eosinofilia, espessadas, ramificadas e de aspeto em dentes de serra. Os achados clinicopatológicos foram compatíveis com elastose perfurante serpiginosa secundária à $D$-penicilamina. Estima-se que a elastose perfurante serpiginosa ocorra em $1 \%$ dos doentes medicados com D-penicilamina. Bloqueando direta ou indiretamente as ligações cruzadas de desmosina da elastina, a D-penicilamina leva à síntese de fibras elásticas anómalas dérmicas, mas também extracutâneas. A elastose perfurante serpiginosa pode ser a primeira manifestação de um processo degenerativo multissistémico do tecido conjuntivo elástico.

Palavras-chave: Degeneração Hepatolenticular; Doenças da Pele/induzida quimicamente; Penicilamina; Quelantes/uso terapêutico.

\section{ABSTRACT}

Elastosis perfurans serpiginosa is a rare perforating dermatosis found primarily in adolescents and young adults, characterized by transepidermal elimination of abnormal elastic fibers. The only drug known capable of inducing elastosis perfurans serpiginosa is D-penicillamine. We report the case of a 52 year-old woman with keratotic papules arranged in an annular pattern with central clearing and centrifugal growth, located in the anterior cervical region. The patient was chronically treated with D-penicillamine for Wilson disease. Lesion biopsy showed transepidermal elimination of thickened, eosinophilic, branched, sawtooth-like elastic fibers. The clinical and pathological findings were consistent with elastosis perfurans serpiginosa secondary to D-penicillamine. It is estimated that elastosis perfurans serpiginosa occurs in $1 \%$ of patients treated with D-penicillamine. By blocking directly or indirectly the desmosine cross-links between elastin molecules, D-penicillamine leads to the synthesis of abnormal dermal and extracutaneous elastic fibers. Elastosis perfurans serpiginosa may be the first manifestation of a multisystemic degenerative process of elastic connective tissue. Keywords: Chelating Agents/therapeutic use; Hepatolenticular Degeneration; Penicillamine; Skin Diseases/chemically induced.

\section{INTRODUÇÂO}

A elastose perfurante serpiginosa (EPS) é uma entidade rara que pertence ao grupo das "dermatoses perfurantes primárias" onde se incluem a colagenose perfurante reativa, as foliculites perfurantes e a doença de Kyrle. ${ }^{1}$

O conceito "dermatose perfurante adquirida" é usado por alguns autores, em sentido lato, para incluir as formas primárias que surgem no contexto de diabetes mellitus, doença renal crónica, ou ambas. ${ }^{2}$

As dermatoses perfurantes são assim designadas por partilharem o achado histológico de perfuração epidérmica com eliminação transepidérmica de tecido conjuntivo dérmico, e são em geral divididas de acordo com o tipo material expelido e o local da perfuração. Na colagenose perfurante reativa são eliminadas sobretudo fibras de co- lagénio, na EPS fibras elásticas, enquanto nas foliculites perfurantes o processo de eliminação ocorre através do epitélio do folículo piloso. ${ }^{1-3}$

A EPS é encontrada predominantemente em adolescentes e adultos jovens, sendo até três vezes mais frequente no sexo masculino. ${ }^{1}$

Esta entidade tem sido tradicionalmente classificada, por ordem decrescente de frequência, como idiopática - a maioria dos casos, reativa - cerca de $25-40 \%$, ou excecionalmente fármaco-induzida. ${ }^{3-5}$

Entre os casos idiopáticos tem sido descrita associação familiar, com formas hereditárias autossómicas dominantes ou recessivas. ${ }^{5} \mathrm{~A}$ forma reativa pode ocorrer associada a síndrome de Down, síndrome de Marfan, síndrome de

1. Serviço de Dermatologia. Hospitais da Universidade de Coimbra. Centro Hospitalar e Universitário de Coimbra. Coimbra. Portugal.

$\triangle$ Autor correspondente: André Pinho. andrecastropinho@gmail.com

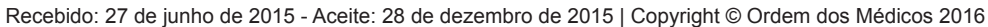




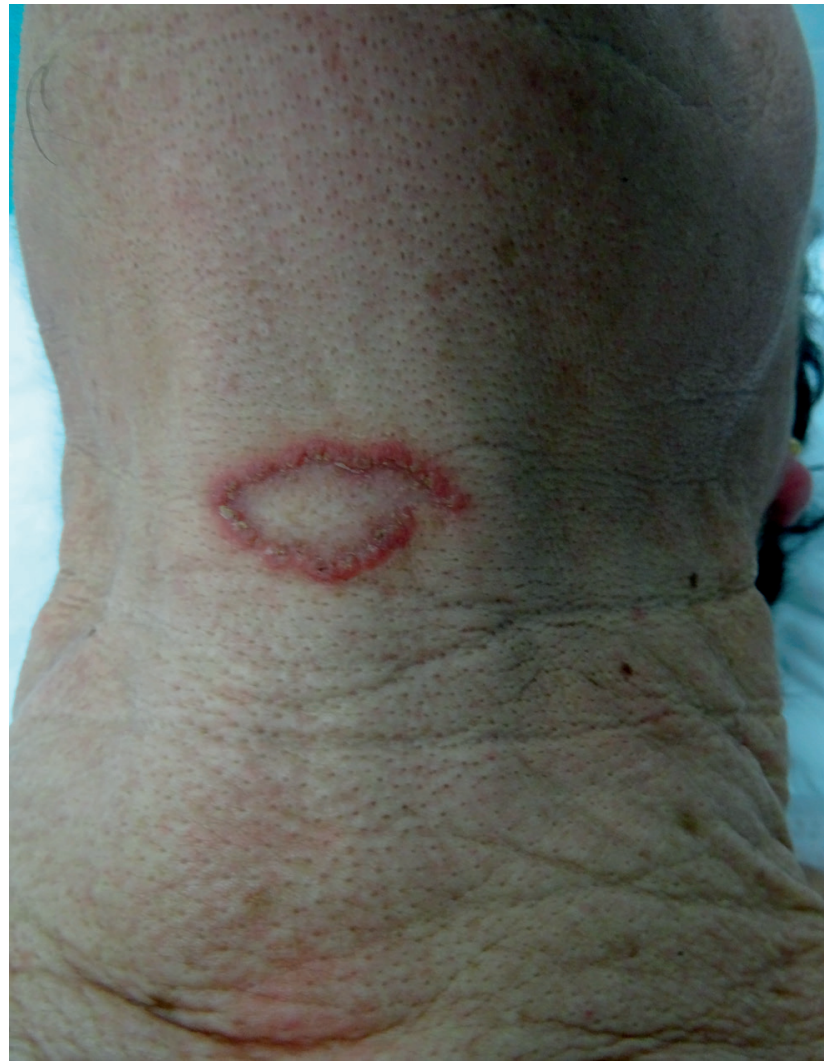

Figura 1 - Pápulas hiperqueratósicas confluentes, com disposição anular ao nível da face anterior do pescoço

Rothmund-Thomson, doença de Ehlers-Danlos, acrogeria, pseudoxantoma elástico, osteogénese imperfeita, ou esclerodermia. ${ }^{6} \mathrm{O}$ único medicamento conhecido capaz de induzir EPS é a D-penicilamina, quelante do cobre classicamente utilizado para tratamento de doença de Wilson. ${ }^{7}$

Apresentamos um caso que ilustra o aspeto clínico característico de EPS, com alterações histológicas típicas nas fibras elásticas secundárias à terapêutica de longa duração com D-penicilamina.

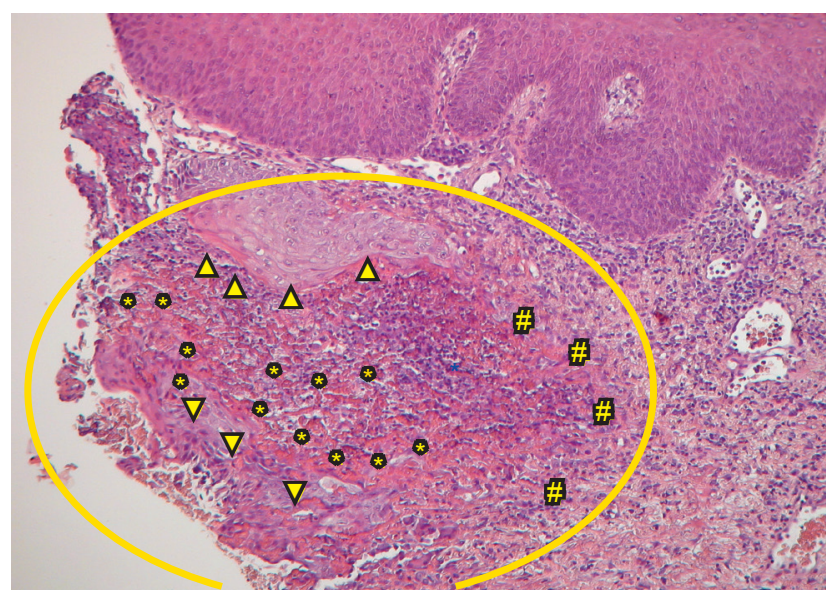

Figura 3 - Coloração hematoxilina-eosina: área focal na derme superficial (círculo) contendo fibras elásticas anómalas $\left(^{*}\right)$, circundadas por epitélio acantósico (setas) e por paliçada de células linfomononucleadas (\#).

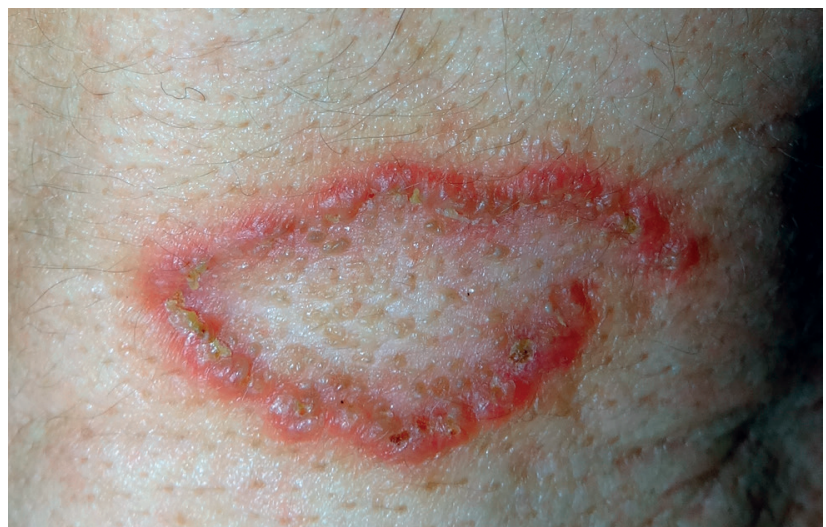

Figura 2 - Áreas de hiperqueratose folicular sobre a pele normal do centro da lesão

\section{CASO CLÍNICO}

Doente do sexo feminino, de 52 anos, raça caucasiana, é enviada à consulta de Dermatologia por pápulas queratósicas da região cervical anterior, com um ano de evolução e que ao longo do tempo apresentaram crescimento centrífugo.

Ao exame objetivo observava-se placa anular única com cerca de $5 \mathrm{~cm}$, cujo bordo era composto por pápulas confluentes de superfície rosada e queratósica e o centro composto por pele normal, embora com áreas esparsas de hiperqueratose folicular (Figs. 1 e 2).

Trata-se de doente com diagnóstico de doença de Wilson aos 17 anos e que estava, desde essa altura, medicada com D-penicilamina, na dose de 900 a 1200 mg/dia. À data da avaliação apresentava hepatopatia crónica, movimentos coreico-distónicos e alterações do comportamento, secundários à doença de base.

A biópsia incisional lesional revelou, na coloração hematoxilina-eosina, área focal ao nível da derme superficial contendo fibras elásticas anómalas com aumento da eosinofilia, circundadas por paliçada de células linfomononucleadas incluindo células gigantes multinucleadas, sendo englobada por uma área de epitélio acantósico - aspetos

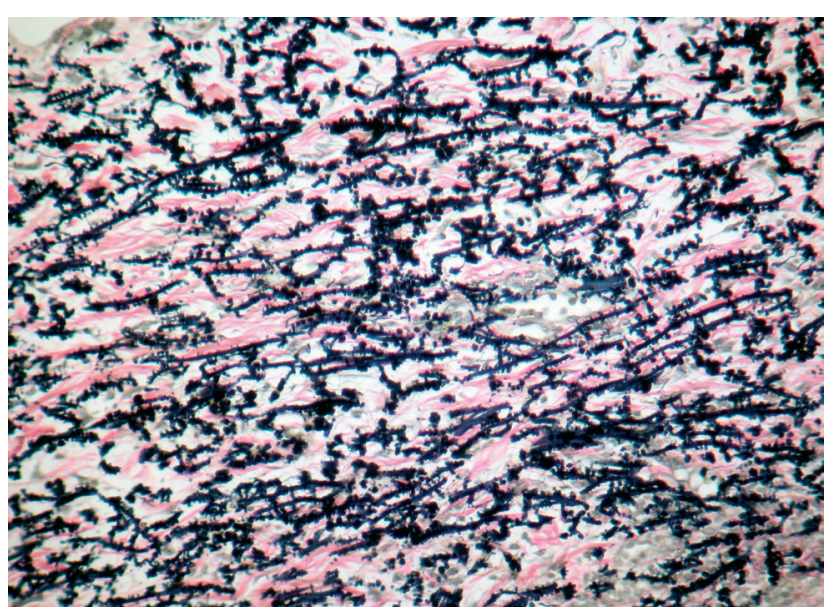

Figura 4 - Coloração Verhoeff: fibras elásticas espessadas, ramificadas, fragmentadas e de aspeto em dentes de serra - 'bramble bush' ou 'lumpy-bumpy'. 
sugestivos de eliminação transepidérmica (Fig. 3). À coloração Verhoeff foram detetadas fibras elásticas espessadas, frequentemente ramificadas, fragmentadas e com aspeto em dentes de serra (Fig. 4).

O diagnóstico de EPS secundária à D-penicilamina foi estabelecido, após correlação clinicopatológica.

A ecografia abdominal e endoscopia digestiva alta recentes não revelaram aneurismas ou outras alterações sugestivas de elastose sistémica. Sugerimos a realização de tomografia computorizada torácica.

A doente declinou terapêutica local para lesão. Propusemos a troca de D-penicilamina por trientina, ou por sais de zinco.

\section{DISCUSSÃO}

A EPS foi reconhecida pela primeira vez por Lutz em 1953, que a classificou como "queratose folicular serpiginosa", tendo em conta o aspeto morfológico das lesões. Em 1955 Miescher identificou elastina no material eliminado e designou a doença "elastoma intrapapilar perfurante verruciforme". ${ }^{3}$

Especula-se que a D-penicilamina cause EPS por dois mecanismos: Atuando indiretamente por depleção do cobre necessário à atuação da lisil-oxidase, enzima importante para estabelecer ligações cruzadas de desmosina - ligações covalentes entre as moléculas de lisina dos monómeros de (tropo)elastina - que estabilizam a formação das fibras elásticas. Atuando diretamente por bloqueio químico das moléculas de lisina. Na presença de D-penicilamina as moléculas de elastina recém-sintetizadas são instáveis e alvo de rápida proteólise e reação de corpo estranho. 1,7-10 A ocorrência síncrona de cutis laxa e pseudoxantoma elástico em doentes com EPS induzida pela D-penicilamina pode dever-se ao dano às fibras elásticas pelos mesmos mecanismos. 8,10

Estima-se que $1 \%$ dos doentes medicados durante décadas com D-penicilamina venham a desenvolver EPS, daí a associação clássica com doença de Wilson, mas também artrite reumatoide, cistinúria, ou esclerodermia. ${ }^{8,9}$

A extrusão de fibras elásticas traduz-se clinicamente no aparecimento de pápulas eritematosas ou cor de pele, hiperqueratósicas, com cerca de $2-5 \mathrm{~mm}$, dispostas de forma serpiginosa, anular, ou arciforme. ${ }^{1,9}$

As lesões surgem sobretudo no pescoço, embora possam ocorrer na face, braços, flexuras, ou mesmo no pénis, sendo geralmente assintomáticas. ${ }^{8}$

O achado histológico mais proeminente da EPS é a ocorrência de canais perfurantes estreitos transepidérmicos, ou perifoliculares que se estendem proximalmente a partir da derme, de forma linear ou contorcida, e que no interior contém uma mistura de fibras elásticas eosinofílicas degeneradas, resíduos celulares basofílicos e células inflamatórias. ${ }^{1}$

Elastose dérmica, com aumento do número e espessura das fibras elásticas dérmicas é também observada. ${ }^{1} \mathrm{Um}$ infiltrado inflamatório crónico, com células gigantes multi- nucleadas formando granulomas pode estar presente. A epiderme é frequentemente acantósica e hiperqueratósica.

A EPS induzida pela D-penicilamina distingue-se das outras formas de EPS pelo aspeto caraterístico em dentes de serra das fibras elásticas, também conhecido como 'bramble bush' ou 'lumpy-bumpy', com depósitos de cálcio nas fibras eliminadas. ${ }^{1,11}$

Além da elastose dérmica a D-penicilamina pode induzir elastose sistémica, com dano às fibras elásticas das artérias, mucosa oral, trato respiratório superior, pulmão, ou endocárdio, gerando complicações potencialmente graves, como formações aneurismáticas e cistos pulmonares. ${ }^{8}$

A EPS pode persistir por vários anos, regredir espontaneamente, ou mesmo surgir após suspensão da D-penicilamina, provavelmente pela sua depuração lenta do organismo. ${ }^{10}$ Das várias opções terapêuticas descritas nenhuma é consistentemente eficaz e a maioria gera resultados dececionantes. Estas incluem isotretinoína oral, imiquimod, tretinoína, tazaroteno, ou calcipotriol tópicos, crioterapia, curetagem com eletrocirurgia, fototerapia, ou laser de dióxido de carbono, erbium-YAG, ou luz pulsada. ${ }^{12}$

Não menos importante é suspensão da D-penicilamina e troca por trientina, um quelante de cobre com menor toxicidade, ou por sais de zinco, que diminuem a absorção intestinal de cobre. ${ }^{7,10}$

Realçamos com este caso a importância do reconhecimento desta dermatose clássica no contexto de terapêutica com D-penicilamina, ainda usada na doença de Wilson, e que pode ser uma manifestação cutânea isolada ou a primeira manifestação de um processo degenerativo multissistémico do tecido conjuntivo elástico.

\section{OBSERVAÇÕES}

Este tema foi previamente apresentado na Reunião de Primavera da Sociedade Portuguesa de Dermatologia e Venereologia, 22 e 23 Maio 2015, Lisboa.

\section{PROTECÇÃO DE PESSOAS E ANIMAIS}

Os autores declaram que os procedimentos seguidos estavam de acordo com os regulamentos estabelecidos pelos responsáveis da Comissão de Investigação Clínica e Ética e de acordo com a Declaração de Helsínquia da Associação Médica Mundial.

\section{CONFIDENCIALIDADE DOS DADOS}

Os autores declaram ter seguido os protocolos do seu centro de trabalho acerca da publicação dos dados de doentes.

\section{CONFLITO DE INTERESSES}

Os autores declaram não ter nenhum conflito de interesses relativamente ao presente artigo.

\section{FONTES DE FINANCIAMENTO}

Não existiram fontes externas de financiamento para a realização deste artigo. 


\section{REFERÊNCIAS}

1. Lewis KG, Bercovitch L, Dill SW, Robinson-Bostom L. Acquired disorders of elastic tissue: part I. Increased elastic tissue and solar elastotic syndromes. J Am Acad Dermatol. 2004;51:1-21; quiz 2-4.

2. Rapini RP. Acquired Perforating Dermatosis. Arch Dermatol. 1989;125:1074.

3. Patterson JW. The perforating disorders. J Am Acad Dermatol. 1984;10:561-81.

4. Vearrier D, Buka RL, Roberts B, Cunningham BB, Eichenfield LF Friedlander SF. What is standard of care in the evaluation of elastosis perforans serpiginosa? A survey of pediatric dermatologists. Pediatr Dermatol. 2006;23:219-24.

5. Langeveld-Wildschut EG, Toonstra J, van Vloten WA, Beemer FA Familial elastosis perforans serpiginosa. Arch Dermatol. 1993;129:2057

6. Mehta RK, Burrows NP, Payne CM, Mendelsohn SS, Pope FM, Rytina E. Elastosis perforans serpiginosa and associated disorders. Clin Exp Dermatol. 2001;26:521-4
7. Hellriegel S, Bertsch HP, Emmert S, Schön MP, Haenssle HA. Elastosis perforans serpiginosa: A case of a penicillamine-induced degenerative dermatosis. JAMA Dermatol. 2014;150:785-7.

8. Chuang Y-N, Yao C-A, Chiu T-M, Yang K-C, Lin Y-M, Hsu H-C D-Penicillamine induced elastosis perforans serpiginosa with involvement of glans penis. Dermatologica Sinica. 2014;32:93-6.

9. Tovaru S, Parlatescu I, Dumitriu AS, Bucur A, Kaplan I. Oral complications associated with D-penicillamine treatment for Wilson disease: a clinicopathologic report. J Periodontol. 2010;81:1231-6.

10. Na SY, Choi M, Kim MJ, Lee JH, Cho S. Penicillamine-induced Elastosis Perforans Serpiginosa and Cutis Laxa in a Patient with Wilson's Disease. Ann Dermatol. 2010;22:468-71.

11. Pereira ACF, Baeta IGR, Costa Júnior SRd, Gontijo Júnior OM, Vale ECSd. Elastose perfurante serpiginosa em portadora da síndrome de Down. Anais Bras Dermatol. 2010;85:691-4.

12. Lee S-H, Choi Y, Kim S-C. Elastosis Perforans Serpiginosa. Ann Dermatol. 2014;26:103-6. 